\title{
ANESTESIA DE UMA LONTRA (Lutra longicaudis - CARNIVORA, MUSTELIDAE) PELA ASSOCIAÇÃO DE XILAZINA, TILETAMINA, ZOLAZEPAM E ATROPINA - DOSES CALCULADAS POR MEIO DE EXTRAPOLAÇÃO ALOMÉTRICA INTERESPECÍFICA J .R. PACHALY ${ }^{1}$; R.R. LANGE ${ }^{2}$; M.L. JAVOROVSKI ${ }^{2}$; E.M.G. CIFFONI ${ }^{1}$ \\ ${ }^{1}$ Departamento de Medicina Veterinária da Universidade Paranaense - UNIPAR, Umuarama - PR. \\ ${ }^{2}$ Departamento de Zoológico da Prefeitura Municipal de Curitiba.
}

Um macho adulto de Lutra longicaudis pesando $8 \mathrm{~kg}$ foi anestesiado para ser submetido a tratamento odontológico, no Zoológico de Curitiba, em dezembro de 1995. Optou-se pela combinação de cloridrato de tiletamina e zolazepam (Zoletilß), cloridrato de xilazina (Rompun $\left.{ }^{\circledR}\right)$ e sulfato de atropina, com a finalidade de induzir anestesia profunda acompanhada por completo miorrelaxamento, com reduzidos riscos de bradicardia e hipotensão. As doses a administrar foram calculadas por meio de extrapolação alométrica da dose recomendada para uma espécie animal já estudada, estabelecendo-se como modelo um gato de $4 \mathrm{~kg}$. A tabela abaixo resume os dados de cálculo.

\begin{tabular}{c|c|c|c}
\hline Droga & $\begin{array}{c}\text { Dose recomendada para } \\
\text { um gato de } 4 \mathrm{~kg}\end{array}$ & $\begin{array}{c}\text { Dose extrapolada para uma } \\
\text { lontra de } 8 \mathrm{~kg}\end{array}$ & $\begin{array}{c}\text { Dose total a administrar a uma } \\
\text { lontra de } 8 \mathrm{~kg}\end{array}$ \\
\hline Zoletil & $10 \mathrm{mg} / \mathrm{kg}$ & $8,409 \mathrm{mg} / \mathrm{kg}$ & $67,272 \mathrm{mg} \rightarrow 67,3 \mathrm{mg}$ \\
Xilzazina & $2 \mathrm{mg} / \mathrm{kg}$ & $1,682 \mathrm{mg} / \mathrm{kg}$ & $13,456 \mathrm{mg} \rightarrow 13,5 \mathrm{mg}$ \\
Atropina & $0,05 \mathrm{mg} / \mathrm{kg}$ & $0,042 \mathrm{mg} / \mathrm{kg}$ & $0,336 \mathrm{mg} \rightarrow 0,34 \mathrm{mg}$ \\
\hline
\end{tabular}

As doses totais de cada uma das drogas

foram acondicionadas conjuntamente em uma seringa, sendo a mistura administrada por via intramuscular. Três minutos após a injeção o paciente apresentou decúbito, com perda da reação postural de endireitamento. Com o protocolo posológico empregado obteve-se anestesia de excelente qualidade, profundo miorrelaxamento e abolição da sensibilidade dolorosa. Foi realizada remoção completa de tártaro dentário e exodontia do primeiro molar superior, seguida por curetagem alveolar. Os procedimentos clínicos foram finalizados 92 minutos após a injeção, e o animal foi colocado em uma caixa de transporte, onde permaneceu em observação até recobrar a capacidade de ambulação, o que ocorreu 273 minutos após a injeção. Parâmetros fisiológicos foram monitorizados a cada 10 minutos após a injeção, até o $90^{\circ}$ minuto. A freqüência cardíaca variou entre 156 e 228 b.p.m. (média de 182,66 b.p.m.) e a freqüência respiratória variou entre 14 e 22 m.p.m. (média de 16,28 m.p.m.). A temperatura retal variou entre 38,5 e $41,5^{\circ} \mathrm{C}$ (média de $39,37^{\circ} \mathrm{C}$ ). 